\title{
O Supremo e os precedentes constitucio- nais: como fica a sua eficácia após o Novo Código de Processo Civil ${ }^{*}$
}

\section{The Brazilian Supreme Court and its precedents on constitutional law: what changes after the New Procedural Code}

\begin{abstract}
Resumo
Este artigo busca examinar os efeitos produzidos pelos precedentes do Supremo Tribunal Federal, em matéria constitucional, antes e depois da vigência do Novo Código de Processo Civil (Lei ${ }^{\circ}$ 13.105/2015). Demonstra-se que, com o novo código, aumentam os casos de precedentes normativos. Explica-se o que são precedentes normativos e como se opera com eles, a partir de quatro conceitos: ratio decidendi (holding), considerações marginais (obiter dicta), distinção e superação de precedentes. Ao final, faz-se um breve balanço dos aspectos positivos e negativos decorrentes da ampliação do rol dos precedentes normativos no Direito constitucional brasileiro e da influência que estes últimos produzem na interação entre o STF e as demais instâncias judiciais.
\end{abstract}

Palavras-chave: Supremo Tribunal Federal. Jurisdição constitucional. Novo Código de Processo Civil (Lei no 13.105/2015). Eficácia dos precedentes. Precedentes vinculantes. Precedentes normativos. Razão de decidir, ratio decidendi (holding). Considerações marginais (obiter dictum). Distinção entre precedentes. Superação de precedentes. Segurança jurídica, isonomia e eficiência do Judiciário.

\begin{abstract}
This paper examines the effects produced by Brazilian Supreme Court's decisions on constitutional matters, before and after the New Procedural Code (Law n\# 13.105/2015). It demonstrates that the new code increases the hypothesis of binding precedents and explains their use with basis in four concepts: ratio decidendi (holding), obiter dictum, distinguishing and overruling of judicial precedents. The article concludes with an analysis of the positive and negative aspects of the new code on this matter, and about its consequences to the relationship between the Brazilian Supreme Court and the others Brazilian judges and courts.
\end{abstract} do Estado do Rio de Janeiro, Procuradora do Estado do Rio de Janeiro, Parecerista. Atualmente, atua como Assessora de Ministro do Supremo Tribunal Federal. Professora de Direito Constitucional do UniCEUB.

Keywords: Brazilian Supreme Court. Constitutional jurisdiction. New Brazilian Procedural Code (Law n\# 13.105/2015). Effects of constitutional precedents. Binding precedents. Ratio decidendi (holding). Obiter dictum. Distinguishing. Overruling. Legal stability, equality and judicial efficiency. 


\section{Introdução}

O presente artigo tem o propósito de examinar a relevância reconhecida aos precedentes judiciais sobre matéria constitucional no ordenamento jurídico brasileiro e o que muda com as alterações introduzidas pelo Novo Código de Processo Civil. Com esse objetivo se examinarão: (i) os tipos de eficácia de que podem ser dotados os precedentes; (ii) a eficácia dos precedentes brasileiros em matéria constitucional, antes da vigência do CPC/2015; (iii) a eficácia dos precedentes em matéria constitucional, após a vigência do CPC/2015; (iv) como se opera com precedentes e quais os desafios que serão enfrentados pelos tribunais nesse tema. Ao final, faz-se um $(v)$ juízo crítico da opção adotada pelo legislador, de ampliar os casos de precedentes normativos, e ( $v i)$ demonstra-se que o bom funcionamento do sistema dependerá do desenvolvimento de uma cultura de respeito aos precedentes não apenas pelas cortes vinculadas, mas também pelo STF.

\section{Os tipos de eficácia dos precedentes: eficácia normativa, eficácia persuasiva e eficácia in- termediária}

Uma decisão judicial pode produzir três tipos de eficácia. Pode, em primeiro lugar, produzir um precedente de caráter normativo, também referido, genericamente, como precedente vinculante ${ }^{2}$, cuja característica essencial é ser de observância obrigatória pelos órgãos judiciais inferiores. O desrespeito a tais precedentes, no direito brasileiro, enseja a propositura de reclamação, diretamente na corte que o editou, permitindo que a parte a acesse per saltum, a fim de obter a cassação da decisão violadora do entendimento da corte vinculante.

Um julgado pode, por outro lado, produzir um

É válido esclarecer que toda decisão judicial é vinculante, ou seja, produz uma determinação a ser obrigatoriamente observada. Algumas decisões vinculam apenas as partes (eficácia inter partes). Outras vinculam também terceiros que não são partes (eficácia erga omnes). Entretanto, a expressão "precedente vinculante" é utilizada pela comunidade jurídica como sinônimo de "precedente normativo", para referir-se a julgados que produzem efeitos não apenas vinculantes, mas também contra todos (erga omnes), obrigando, portanto, terceiros que não atuaram no feito. Embora o uso da expressão precedente vinculante como sinônimo de precedente normativo não seja rigorosamente técnico, a expressão será empregada neste trabalho com este último significado, em virtude de seu uso corrente. precedente de eficácia meramente persuasiva, ao manifestar um entendimento que obriga às partes de uma ação apenas, mas que não tem de ser obrigatoriamente observado pelos demais órgãos judiciais, no julgamento de casos diversos, ainda que tenham por objeto questão jurídica idêntica. O julgado com esse tipo de eficácia não é, de todo, irrelevante: presta-se a apoiar argumentativamente a defesa de uma parte ou um posicionamento judicial no mesmo sentido; demonstra que a tese de direito em que se funda já foi acolhida por um órgão judicial; pode dar ensejo a uma série de decisões e resultar na consolidação de uma linha jurisprudencial. Este tipo de eficácia contribui, em alguma medida, para a redução da indeterminação do Direito.

Há, por fim, os precedentes dotados de uma eficácia que se denominará, neste artigo, impositiva intermediária, que se caracteriza por uma decisão ou por um conjunto de decisões que produzem efeitos para além do caso julgado, ainda que não tenham que ser obrigatoriamente seguidos pelos demais órgãos judiciais ou ainda que as decisões delas divergentes não ensejem a propositura de reclamação. Os julgados com eficácia impositiva intermediária, portanto, geram efeitos cuja força e abrangência se situam entre a eficácia normativa e a eficácia meramente persuasiva ${ }^{3}$.

A classificação de precedentes aqui proposta apresenta categorias e critério de classificação que favorecem o exame da eficácia dos julgados do STF em matéria constitucional. No contexto de um ordenamento jurídico que não tem uma cultura de respeito a precedentes obrigatórios, como o brasileiro, o mecanismo que efetivamente assegura o caráter normativo das decisões judiciais é a possibilidade de ajuizamento de reclamação, diretamente na corte vinculante, em caso de seu descumprimento, para que a decisão seja cassada. Essa é a razão que motivou a diferenciação, proposta acima, entre precedentes normativos (que têm de ser seguidos até por quem não foi parte no processo, sob pena de serem cassados por reclamação) e precedentes com eficácia intermediária (que produzem efeitos para além do caso em que foram proferidos, devem ser seguidos pelas demais instâncias, mas cuja inobservância não possibilita o ajuizamento de reclamação e que, por isso, não têm a mesma força impositiva dos julgados normativos). Considerou-se efetivamente que a reclamação é o mecanismo de que se valeu o legislador brasileiro para conferir eficácia máxima a uma decisão e induzir à criação de uma cultura de respeito a precedentes judiciais obrigatórios. Em sentido semelhante, sobre a função a ser desempenhada pela reclamação no Novo Código de Processo Civil: "até que as Cortes Supremas, as Cortes de Justiça e os juízes de primeiro grau assimilem uma efetiva cultura do precedente judicial, é imprescindível que se admita a reclamação com função de outorga de eficácia de precedente" (MARINONI, Luiz Guilherme; ARENHART, Sérgio Cruz; MITIDIERO, Da- 


\section{A eficácia dos precedentes no panorama atu- al: antes da vigência do Novo Código de Pro- cesso Civil (Lei no 13.105/2015)}

O ordenamento constitucional brasileiro contempla os três tipos de precedentes descritos acima ${ }^{4}$. No panorama atual, em que ainda não se encontra em vigor o Novo Código de Processo Civil (Lei no 13.105/2015) ${ }^{5}$, pode-se afirmar que as decisões proferidas em sede de controle concentrado da constitucionalidade geram precedentes normativos, pois devem ser necessariamente observadas por todos os demais órgãos judiciais, sob pena de cassação dos julgados que delas divergirem, mediante reclamação. O mesmo tratamento é dado, ainda, às súmulas vinculantes, verbetes que sintetizam reiteradas decisões proferidas sobre um mesmo tema constitucional e cujo descumprimento também dá ensejo à reclamação no STF.

Por outro lado, não se admite a propositura de re-

niel. Código de Processo Civil comentado. São Paulo: Revista dos Tribunais, 2015. p. 920). Nos ordenamentos jurídicos que já desenvolveram a cultura de respeito aos precedentes judiciais, os precedentes normativos e os precedentes meramente persuasivos dominam a cena. Não há necessidade de instituir um mecanismo como a reclamação para que os precedentes das cortes vinculantes sejam cumpridos. Por isso, em países do common law, não faz sentido utilizar a reclamação como critério distintivo entre os tipos de precedentes. Os precedentes proferidos pelas cortes vinculantes têm caráter normativo para as cortes vinculadas, sem necessidade de outros recursos assecuratórios de tal eficácia. Os precedentes produzidos pela primeira instância ou por outros estados, em casos de multiplicidade de jurisdições estaduais, têm mera eficácia persuasiva. E é possível falar, muito residualmente, em precedentes com eficácia impositiva intermediária, quando um precedente é aplicado pela própria corte que o proferiu. Trata-se de precedente obrigatório para as instâncias vinculadas e de entendimento que deve ser observado pela corte vinculante inclusive para além do caso em que o afirmou. Abre-se, contudo, para a última a possibilidade de superá-lo (MELLO, Patrícia Perrone Campos. Precedentes: o desenvolvimento do direito no constitucionalismo contemporâneo. Rio de Janeiro: Renovar, 2008. p. 65).

4 V. MELLO, Patrícia Perrone Campos. Precedentes: o desenvolvimento do direito no constitucionalismo contemporâneo. Rio de Janeiro: Renovar, 2008; FINE, Toni M. O uso do precedente e o papel do princípio do Stare Decisis no sistema legal norte-americano. Revista dos Tribunais, São Paulo, v. 89, n. 782, p. 90-96, dez. 2000; SILVA, Celso de Albuquerque. Do efeito vinculante: sua legitimação e aplicação. Rio de Janeiro: Lumen Juris, 2005; SOUZA, Marcelo Alves Dias de. Do precedente judicial à súmula vinculante. Curitiba: Juruá, 2006.

5 Nos termos do CPC/2015, art. 1.045, o novo código entrará em vigor em março de 2016. clamações contra decisões que deixem de observar os julgados proferidos pelo Supremo em casos de repercussão geral, tampouco é possível o manejo de tal instrumento contra julgados que divirjam da jurisprudência dominante do próprio tribunal ou dos tribunais superiores ${ }^{6}$. Espera-se, contudo, que tais entendimentos sejam seguidos e, portanto, que, em alguma medida, produzam efeitos para além dos casos em que foram afirmados, por uma questão de coerência sistêmica.

De acordo com as normas processuais em vigor, as decisões do pleno do STF ou dos tribunais que declarem a inconstitucionalidade de uma lei, dispensam a exigência de reserva de plenário para que, em um novo caso, se reconheça a inconstitucionalidade da mesma norma ${ }^{7}$. A súmula e a jurisprudência consolidada no tribunal ou nos tribunais superiores possibilitam a inadmissão, o desprovimento ou o provimento monocrático, pelo relator, de recurso com elas (in)compatíveis, sem a necessidade de levar a questão novamente a um órgão colegiado. Pode-se afirmar, portanto, que, no sistema atual, as decisões proferidas em repercussão geral, as decisões do pleno do STF ou dos tribunais que declarem a inconstitucionalidade de uma norma, as súmulas e a jurisprudência consolidada nos tribunais configuram precedentes de eficácia intermediária.

Por fim, caracteriza-se como precedente com eficácia persuasiva toda e qualquer decisão que não se enquadre nas categorias anteriores e, portanto, qualquer julgado cujas razões sejam aplicáveis exclusivamente às partes do feito e que ainda não adquiriram o caráter de jurisprudência consolidada.

À luz do atual sistema, os precedentes com eficácia persuasiva são a regra e os precedentes com eficácia nor-

$6 \quad$ V. STF, DJe, 3 jul. 2011, Rcl 10793-SP, rel. Ministra Ellen Gracie. V. ainda, BARROSO, Luis Roberto. O controle de constitucionalidade no direito brasileiro. São Paulo: Saraiva, 2015. Em defesa do cabimento de reclamação no sistema difuso de controle das constitucionalidade das normas: MARTINS, Yves Gandra; MENDES, Gilmar Ferreira. Eficácia das decisões do Supremo Tribunal Federal. Cadernos de Direito Tributário e Finanças Públicas, Revista dos Tribunais, São Paulo, v. 1, n. 2, p. 7-11, jan./mar, 1993; MENDES, Gilmar Ferreira. O papel do Senado Federal no controle de constitucionalidade: um caso clássico de mutação constitucional. Revista de Informação Legislativa, Senado Federal, Brasília, v. 162, p. 149-168.

7 Nos termos do art. 97, CPC: “Art. 97. Somente pelo voto da maioria absoluta de seus membros ou dos membros do respectivo órgão especial poderão os tribunais declarar a inconstitucionalidade de lei ou ato normativo do Poder Público". 
mativa, a exceção ${ }^{8}$. Tal estado de coisas, acredita-se, seria consequência da raiz romano-germânica do direito brasileiro. No ambiente romano-germânico, a principal fonte do direito é a lei e, como regra, as decisões judiciais aplicam-se apenas às partes de um julgado. No outro pólo, o sistema da common law tem no precedente normativo a principal fonte do Direito. Uma vez proferida uma decisão por uma corte superior, neste último sistema, a tese de direito que a embasa deve, como regra, ser observada por todos os demais órgãos judiciais hierarquicamente inferiores. É indiscutível, contudo, que há um processo de aproximação entre os dois modelos. No common law, passou-se a recorrer à lei, diante da necessidade de alterar marcos regulatórios de forma imediata e sistêmica9 ${ }^{9}$. Nos países cujo direito tem origem romano-germânica, introduziu-se a ideia do precedente normativo, sobretudo em matéria constitucional ${ }^{10}$. Tal aproximação entre os sistemas avança mais alguns importantes passos com o Novo Código de Processo Civil.

\section{Os novos precedentes com eficácia normati- va no $\mathrm{CPC} / 2015$}

O art. 988 do CPC/2015 prevê cinco hipóteses de

8 Essa é a visão tradicional sobre a eficácia das decisões judiciais no ordenamento brasileiro, mas não é a mais precisa. Desde o advento da Constituição de 1988, tem-se assistido a uma progressiva adoção de precedentes normativos em matéria constitucional, merecendo destaque: a ampliação do rol de legitimados para a propositura da ação direta de inconstitucionalidade, a criação da ação declaratória da constitucionalidade, da arguição de descumprimento de preceito fundamental e da súmula vinculante.

9 Para uma demonstração de que o ordenamento jurídico encontra-se em processo progressivo de adoção de precedentes vinculantes e de que, por outro lado, os países que adotam o common law têm produzido soluções legislativas em algumas matérias, v. MELLO, Patrícia Perrone Campos. Precedentes: o desenvolvimento do direito no constitucionalismo contemporâneo. Rio de Janeiro: Renovar, 2008.

10 ALEXY, Robert; DREIER, Ralf. Precedent in the Federal Republic of Germany. In: MACCORMICK, D. Neil; SUMMERS, Robert S. (Org.). Interpreting precedents: a comparative study. England: Dartmouth Publishing Company Limited; Ashgate Publishing Limited, 1997. p. 26-27; TARUFFO, Michele; LA TORRE, Massimo. Precedent in Italy. In: MACCORMICK, D. Neil; SUMMERS, Robert S. (Org.). Interpreting precedents: a comparative study. England: Dartmouth Publishing Company Limited; Ashgate Publishing Limited, 1997. p. 154-155; RUIZ MIGUEL, Alfonso; LAPORTA, Francisco J. Precedent in Spain. In: MACCORMICK, D. Neil; SUMMERS, Robert S. (Org.). Interpreting precedents: a comparative study. England: Dartmouth $\mathrm{Pu}-$ blishing Company Limited; Ashgate Publishing Limited, 1997. p. 272. cabimento de reclamação: a necessidade de (i) preservar a competência do tribunal; de (ii) garantir a autoridade das suas decisões; de (iii) impor a observância de julgado do Supremo Tribunal Federal em controle concentrado de constitucionalidade; de (iv) garantir o respeito de enunciado de súmula vinculante; e de ( $v)$ assegurar o respeito a precedente proferido em julgamento de casos repetitivos ou em incidente de assunção de competência. Os itens (i) a (iv) já comportavam reclamação no sistema atualmente em vigor. A novidade está, portanto, no item ( $v)$, em que se autorizou a propositura de reclamação também para garantir a observância das decisões judiciais proferidas em casos repetitivos e em incidentes de assunção de competência $^{11}$.

\subsection{Casos repetitivos ${ }^{12}$}

O julgamento de casos repetitivos abrange: (i) o incidente de resolução de demandas repetitivas ${ }^{13}$ e (ii) os

11 CPC/2015, art. 988: "Caberá reclamação da parte interessada ou do Ministério Público para: I - preservar a competência do tribunal; II - garantir a autoridade das decisões do tribunal; III - garantir a observância de decisão do Supremo Tribunal Federal em controle concentrado de constitucionalidade; IV - garantir a observância de enunciado de súmula vinculante e de precedente proferido em julgamento de casos repetitivos ou em incidente de assunção de competência”. É importante assinalar a existência de discussão sobre a constitucionalidade da atribuição de efeitos vinculantes a julgados por meio do poder constituinte originário. V., nesse sentido, NERY JUNIOR, Nelson; NERY, Rosa Maria de Andrade. Comentários ao Código de Processo Civil. São Paulo: Revista dos Tribunais, 2015. p. 18391984. Cf., ainda, discussões travadas nos seguintes feitos: STF, ADI 2331, rel. Min. Néri da Silveira, julgamento em curso; STF, DJU, 19.03.2004, AgRg na Rcl 1.880, rel. Min. Maurício Correa; STF, DJU, 21.05.1999, ADC 4, rel. Min. Sydney Sanches.

12 Art. 928, CPC/2015.

13 CPC/2015: "Art. 976. É cabível a instauração do incidente de resolução de demandas repetitivas quando houver, simultaneamente: I - efetiva repetição de processos que contenham controvérsia sobre a mesma questão unicamente de direito; II - risco de ofensa à isonomia e à segurança jurídica. [...]. ํ É incabível o incidente de resolução de demandas repetitivas quando um dos tribunais superiores, no âmbito de sua respectiva competência, já tiver afetado recurso para definição de tese sobre questão de direito material ou processual repetitiva. [...]. Art. 977. O pedido de instauração do incidente será dirigido ao presidente de tribunal: I - pelo juiz ou relator, por ofício; II - pelas partes, por petição; III - pelo Ministério Público ou pela Defensoria Pública, por petição. [...]. Art. 978. O julgamento do incidente caberá ao órgão indicado pelo regimento interno dentre aqueles responsáveis pela uniformização de jurisprudência do tribunal. Parágrafo único. $\mathrm{O}$ órgão colegiado incumbido de julgar o incidente e de fixar a tese jurídica julgará igualmente o recurso, a remessa necessária ou o processo de competência originária de onde se originou o incidente". 
recursos especial e extraordinário repetitivos ${ }^{14}$. Na hipótese do incidente de demandas repetitivas, o relator selecionará dois ou mais casos representativos da controvérsia para a apreciação do órgão colegiado do tribunal. Já no que respeita aos recursos especial e extraordinário, o presidente do tribunal a quo selecionará dois ou mais recursos-paradigma e os encaminhará ao respectivo tribunal superior. A decisão proferida pelos tribunais nas demandas repetitivas vinculam os demais órgãos judiciais, que deverão reexaminar as causas decididas de maneira diversa, de modo a conformá-las ao precedente da corte.

\subsection{Incidente de assunção de competência ${ }^{15}$}

$\mathrm{O}$ incidente de assunção de competência pode ocorrer nos tribunais em caso de julgamento de relevante questão de direito, com grande repercussão social, que não se repita em múltiplos processos. Nessa situação, o relator poderá propor que o feito seja julgado pelo órgão colegiado que o regimento interno indicar, e a decisão proferida em segunda instância vinculará todos os juízes e órgãos fracionários, no âmbito da jurisdição do tribunal. Assim, a decisão proferida em incidente de assunção de competência, por qualquer tribunal, também constituirá precedente normativo, a ser obrigatoriamente observado em casos futuros.

\section{Precedentes com eficácia impositiva interme- diária no CPC/2015}

O art. 927 do CPC/2015 estabelece, ainda, que os

14 CPC/2015: $\S 1$ 응 $\mathrm{O}$ presidente ou o vice-presidente de tribunal de justiça ou de tribunal regional federal selecionará 2 (dois) ou mais recursos representativos da controvérsia, que serão encaminhados ao Supremo Tribunal Federal ou ao Superior Tribunal de Justiça para fins de afetação, determinando a suspensão do trâmite de todos os processos pendentes, individuais ou coletivos, que tramitem no Estado ou na região, conforme o caso".

15 CPC/2015: $\$ 1$ 1O Ocorrendo a hipótese de assunção de competência, o relator proporá, de ofício ou a requerimento da parte, do Ministério Público ou da Defensoria Pública, que seja o recurso, a remessa necessária ou o processo de competência originária julgado pelo órgão colegiado que o regimento indicar. $\$ 2 \mathrm{O} \mathrm{O}$ órgão colegiado julgará o recurso, a remessa necessária ou o processo de competência originária se reconhecer interesse público na assunção de competência. $\$ 3^{\mathrm{o}} \mathrm{O}$ acórdão proferido em assunção de competência vinculará todos os juízes e órgãos fracionários, exceto se houver revisão de tese. $\$ 4^{\circ}$ Aplica-se o disposto neste artigo quando ocorrer relevante questão de direito a respeito da qual seja conveniente a prevenção ou a composição de divergência entre câmaras ou turmas do tribunal”. juízes e os tribunais devem observar, além dos precedentes normativos ${ }^{16}$, também (i) os enunciados das súmulas do Supremo Tribunal Federal, em matéria constitucional, (ii) os enunciados das súmulas do Superior Tribunal de Justiça, em matéria infraconstitucional federal, e (iii) a orientação do plenário ou do órgão especial ao qual tais juízes e/ou tribunais estiverem vinculados ${ }^{17}$. A não observância destes três últimos tipos precedentes não enseja, contudo, a propositura de reclamação. Não se estendeu o cabimento da reclamação a tais hipóteses. Por isso, considera-se a eficácia desses julgados como uma eficácia intermediária entre aquela produzida pelos julgados normativos e os efeitos produzidos por decisões com mera eficácia persuasiva.

Na mesma linha, o juiz pode, independentemente da citação do réu, julgar liminarmente improcedente o pedido que contrariar enunciado de súmula do STF, do STJ ou do tribunal de justiça ${ }^{18}$. Além disso, dispensa-se a remessa necessária, em ação que envolve a Fazenda Pública, e não se exige caução para execução provisória, quando as decisões coincidirem com o entendimento cristalizado em súmula de tribunal superior ${ }^{19}$; autoriza-se o relator, por decisão monocrática, a negar ou a dar provimento a recurso, com base em verbetes do STF e do STJ ${ }^{20}$; e presume-se a repercussão geral sempre que o recurso impugnar acórdão que contraria súmula do Supremo ${ }^{21}$.

Assim, as teses consolidadas em súmulas e, ainda, a orientação do plenário ou do órgão especial dos tribunais constituem entendimentos dotados de eficácia impositiva intermediária à luz do Novo CPC. Tais entendi-

16 São precedentes normativos, como já indicado acima, aqueles correspondentes às decisões proferidas no controle concentrado da constitucionalidade, às súmulas vinculantes, aos julgados em casos repetidos e em incidentes de assunção de competência. Tais decisões são de observância obrigatória pelas demais instâncias, sob pena de cassação do entendimento divergente, mediante reclamação.

17 CPC/2015: "Art. 927. Os juízes e os tribunais observarão: I - as decisões do Supremo Tribunal Federal em controle concentrado de constitucionalidade; II - os enunciados de súmula vinculante; III - os acórdãos em incidente de assunção de competência ou de resolução de demandas repetitivas e em julgamento de recursos extraordinário e especial repetitivos; IV - os enunciados das súmulas do Supremo Tribunal Federal em matéria constitucional e do Superior Tribunal de Justiça em matéria infraconstitucional; V - a orientação do plenário ou do órgão especial aos quais estiverem vinculados".

18 Art. 332, CPC/2015.

19 Art. $496, \$ 4^{\circ}$, I, e art. 521, IV, CPC/2015.

20 Art. 932, IV, (a), CPC/2015.

$21 \quad$ Art. $1.035, \$ 3^{\circ}, \mathrm{I}, \mathrm{CPC} / 2015$. 
mentos produzem efeitos que transcendem os casos concretos em que foram proferidos e devem ser cumpridos pelos demais órgãos judiciais, ainda que não se assegure o instrumento da reclamação para cassar as decisões que deixem de observá- $\operatorname{los}^{22}$.

\section{Como se extrai uma norma ou um precedente de uma decisão judicial? Como se opera com precedentes normativos?}

Mas o que exatamente quer dizer ter obrigação de observar um precedente? Como se extrai de um julgado a "norma" que orientará os casos posteriores? Como se opera com precedentes normativos? Há cinco conceitos fundamentais para a operação com precedentes. São eles: (i) a ratio decidendi (holding), (ii) o obiter dictum, (iii) a distinção entre precedentes e (iv) a superação de precedentes.

\subsection{Ratio decidendi (holding) a) Definição da ratio decidendi}

A ratio decidendi corresponde à razão de direito, à tese, à interpretação afirmada pelo tribunal para solucionar uma demanda específica ${ }^{23}$. Ela não abrange a toda a

22 Com classificação semelhante, fazendo alusão a efeitos vinculantes fortes, médios e fracos, v. WAMBIER, Teresa Arruda Alvim et al. Primeiros comentários ao Novo Código de Processo Civil. São Paulo: Revista dos Tribunais, 2015. p. 1318-1322.

23 ALEXANDER, Larry. Constrained by precedent. Southern California Law Review, Los Angeles, v. 63, p. 1-64, Nov. 1989; COLE, Charles D. Stare Decisis na cultura jurídica dos Estados Unidos: o sistema de precedente vinculante do Common Law. Trad. Maria Cristina Zucchi. Revista dos Tribunais, São Paulo, v. 87, n. 752, p. 11-21, jun. 1998; MALTZ, Earl. The nature of precedent. North Carolina Law Review, Chapel Hill, v. 66, p. 367-392, Jan. 1988, p. 372-376; MARSHALL, Geoffrey. What is binding in a precedent. In: MACCORMICK, D. Neil; SUMMERS, Robert S. (Org.). Interpreting precedents: a comparative study. England: Dartmouth Publishing Company Limited; Ashgate Publishing Limited, 1997. p. 503-518; MONAGHAN, Henry Paul. Stare Decisis and constitutional adjudication. Columbia Law Review, New York, v. 88, n. 4, p. 723-773, May 1988, p. 763-766; RE, Edward D. Stare Decisis. Revista de Processo, São Paulo, v. 19, n. 73, p. 47-54, jan./mar. 1994; SCHAUER, Frederick. Precedent. p. 571-605. Disponível em: <www. bsos.umd.edu/gvpt/CITE-IT/Documents/Schauer\%20 1987\%20Precedent.pdf>. Acesso em: 20 dez. 2006; SUMMERS, Robert S. Precedent in the United States (New York State). In: MACCORMICK, D. Neil; SUMMERS, Robert S. (Org.). Interpreting precedents: a comparative study. England: Dartmouth Publishing Company Limited; Ashgate Publishing Limited, 1997. p. 355-406; RORIVE, Isabelle. La rupture de la House of Lords avec un strict principe du fundamentação do julgado. O voto proferido por um relator pode se referir a diversos fundamentos para solucionar a questão que lhe foi posta em determinado sentido. A ratio decidendi corresponderá apenas ao entendimento ou aos argumentos acolhidos pela maioria dos juízes do tribunal e imprescindíveis para justificar o desfecho do caso. Sua identificação depende do exame (i) dos fatos juridicamente relevantes de um caso, (ii) da questão ou das questões direito que ele coloca e (iii) de como tais questões foram enfrentadas pelo colegiado. Corresponde, portanto, à regra de direito utilizada pelo tribunal como uma premissa necessária à solução do caso, à luz das razões adotadas pela maioria de seus membros.

A extração de tal regra de uma decisão concreta está longe de ser uma atividade meramente mecânica ou desprovida de dificuldades. De fato, um relator pode invocar diversos fundamentos para decidir. Se todos os aludidos fundamentos forem acolhidos pela maioria, a ratio decidendi se comporá possivelmente de mais de uma regra de direito ou de uma regra de direito que consolide todos os fundamentos. Em caso de dúvida, um recurso proposto pela literatura sobre o tema é o de inverter a proposição que gera discussão quanto a integrar ou não a ratio decidendi e verificar se a conclusão da decisão se mantém. Se a inversão da proposição não interferir sobre a conclusão do julgado e ela se mantiver, isso significa que a proposição não é necessária para justificar tal conclusão e, por consequência, que não integra o holding.

Em outras circunstâncias, o relator pode levantar diversos argumentos para fundamentar seu voto, mas pode ocorrer de somente um desses argumentos ser aceito pela maioria como razão de decidir. Nessa situação, só o argumento acatado pelo colegiado constituirá a ratio decidendi.

Por fim, pode ocorrer de o relator invocar diversos fundamentos para decidir em determinado sentido, de formar-se um entendimento majoritário com relação ao dispositivo do caso concreto, mas de não haver convergência da maioria dos membros de um colegiado sobre

Stare Decisis dans le contexte d'une réflexion sur l'accélération du temps juridique. In: GERARD, Philippe; OST, François; VAN DE KERCHOVE, Michel (Org.). L'accélération du temps juridique. Bruxelles: Facultés Universitaires Saint-Louis, 2000. p. 807; SILVA, Celso de Albuquerque. Do efeito vinculante: sua legitimação e aplicação. Rio de Janeiro: Lumen Juris, 2005. p. 182-183; SOUZA, Marcelo Alves Dias de. Do precedente judicial à súmula vinculante. Curitiba: Juruá, 2006. p. 125-133. 
as razões que justificam a decisão. Nessa última hipótese, em que só há concordância sobre como a demanda concreta deve ser decidida, mas não sobre a tese de direito apta a fundamentar a conclusão, o caso concreto terá sido decidido sem que um precedente fosse produzido.

Essas considerações demonstram que, para identificar a norma emergente de um precedente, não basta ler a sua ementa ou o voto do relator. É preciso saber como votaram todos os demais membros do tribunal e por que. A ratio decidendi corresponde a uma interpretação, a uma descrição do que a corte decidiu. Por isso, sua determinação pode se revelar altamente complexa e sujeita a discussão.

\section{b) $O$ problema da generalidade da ratio decidendi}

Mas não é só. A maior dificuldade na identificação da ratio decidendi está na determinação do nível de generalidade com que se formulará a regra de direito ${ }^{24}$. Um exemplo auxilia a compreensão do ponto. Imagine-se que Bete, uma turista, foi a um bar e pediu uma garrafa de refrigerante. Na garrafa que lhe foi servida havia uma lagarta morta. Bete não notou a presença da lagarta antes de tomar a bebida. Em razão da ingestão de pedaços da lagarta, Bete teve uma infecção intestinal, precisou ser internada e teve de voltar para casa. Em consequência, ajuizou uma ação pleiteando indenização ao bar que lhe vendeu a bebida, e este foi condenado a ressarci-la dos prejuízos que lhe causou ${ }^{25}$.

Como se poderia formular o holding desse caso?

24 SCHAUER, Frederick. Precedent. p. 571 e ss. Disponível em: <www.bsos.umd.edu/gvpt/CITE-IT/Documents/ Schauer\%201987\%20Precedent.pdf >. Acesso em: $20 \mathrm{dez}$. 2006; DWORKIN, Ronald. O império do direito. Trad. Jefferson Luiz Camargo. São Paulo: Martins Fontes, 2003. p. 111 e ss.; DWORKIN, Ronald. Levando os direitos a sério. Trad. Nelson Boeira. São Paulo: Martins Fontes, 2002. p. 171 e ss.; TRIBE, Laurence H.; DORF, Michael C. On reading the Constitution. Cambridge: Harvard University Press, 1991. p. 97 e ss.; MONAGHAN, Henry Paul. Stare Decisis and constitutional adjudication. Columbia Law Review, New York, v. 88, n. 4, p. 763 e ss.; MALTZ, Earl. The nature of precedent. North Carolina Law Review, Chapel Hill, v. 66, p. 367-392, Jan. 1988. p. 367 e ss.; MARSHALL, Geoffrey. What is binding in a precedent. In: MACCORMICK, D. Neil; SUMMERS, Robert S. (Org.). Interpreting precedents: a comparative study. England: Dartmouth Publishing Company Limited; Ashgate Publishing Limited, 1997. p. 503-518; MACCORMICK, Neil. Argumentação jurídica e teoria do direito. Trad. Waldéa Barcellos. São Paulo: Martins Fontes, 2006.

25 O exemplo inspira-se no caso Donoghue v. Stevenson (1932) A.C. 562, muito conhecido no common law inglês porque sua decisão deu origem à doutrina acerca da responsabilidade por negligência.
Seria possível dizer que: "há obrigação de indenizar um turista sempre que uma bebida servida dentro de uma garrafa lhe causar danos à saúde"; que "há obrigação de indenizar uma pessoa sempre que lhe for servida uma bebida contaminada"; que "o consumidor tem direito à indenização em caso de aquisição de produto ou serviço defeituoso que lhe gere prejuízo"; que "o consumidor tem direito à indenização em caso de vício no bem que adquirido, inclusive em se tratando de imóvel"; ou que "quem quer que gere um prejuízo a alguém deve arcar com a indenização".

Quanto mais ampla for a definição da ratio decidendi, menor liberdade terão os juízes dos casos subsequentes para decidir. Quanto menos ampla for a formulação, maior será a liberdade dos magistrados. O nível de generalidade da decisão deve ser discutido à luz da fundamentação, dos fatos que ela valorizou, dos princípios que ela invocou. É a partir desses aspectos que se poderá definir a "abrangência da decisão proferida pela corte". E, curiosamente, caso ela não defina com muita precisão sua razão de decidir, caberá aos juízes de primeiro grau - portanto, aos juizes supostamente vinculados - interpretar o acórdão em primeira mão e determinar a ratio decidendi que os vincula.

Se o juiz não concordar com a decisão da corte, tenderá a interpretar o precedente em termos restritivos. Se concordar, o formulará em termos mais abrangentes. E, assim, a questão retornará ao tribunal vinculante, por meio de recurso, e este novamente se pronunciará sobre a matéria, através de uma nova decisão que também se sujeitará a interpretação. Nota-se, assim, que a decisão com base em precedentes depende de interpretação. A adoção de precedentes vinculantes altera o objeto da interpretado, que era a norma escrita e que passa a ser o precedente ou ambos. Espera-se que o entendimento formulado no precedente seja um pouco mais determinado do que a norma legislada. Mas não se dispensa a interpretação do precedente para a solução dos casos subseqüentes.

\section{c) A rejeição da eficácia transcendente da fundamen- tação em sede concentrada pelo STF}

Em matéria de controle concentrado da constitucionalidade, a determinação do conteúdo da decisão que adquire caráter normativo conta com mais uma dificuldade. É que o Supremo Tribunal Federal tem entendido que somente o dispositivo das decisões proferidas em ação direta produz efeitos normativos. Tais efeitos não alcançam, no entendimento do STF, os motivos determinantes do julgado. 
Assim, no caso da declaração de inconstitucionalidade de uma taxa municipal, por apresentar fato gerador típico de imposto, o dispositivo da decisão dirá: “o tributo instituído pela Lei X é inconstitucional”; a fundamentação dirá: "taxa não pode ter fato gerador típico de imposto". Mas só o dispositivo vinculará as demais instâncias. Isso significa que só caberá reclamação em caso de aplicação, pelas instâncias inferiores, da Lei X. Não caberá reclamação caso a Lei Y, que instituiu taxa com fato gerador de imposto, seja aplicada, mesmo que seu teor seja idêntico ao da Lei X e ainda que seja inconstitucional pelos mesmos motivos.

A jurisprudência do STF, em sede de controle concentrado, rejeita a idéia de que "os motivos determinantes" da decisão também produzem efeitos normativos. Recusa-se, portanto, a atribuir efeitos normativos à própria ratio decidendi dos julgados proferidos em ação direta. No entendimento da maioria da Corte, a semelhança entre duas leis sempre poderá ser discutida, de forma que, se forem atribuídos efeitos normativos à razão de decidir, o Supremo terá de apreciar, via reclamação, toda e qualquer norma assemelhada a outra eventualmente declarada inconstitucional, a pretexto de que sua aplicação desrespeita a exegese firmada no precedente. Na visão da Corte, seria inviável conferir tal alcance aos julgados proferidos em controle concentrado ou à reclamação ${ }^{26}$.

Afirma-se, ainda, que seria excessivo conferir efeitos normativos a todos os fundamentos da decisão. Nesse ponto, a Corte parece passar ao largo da compreensão de que somente a razão determinante do julgado, como aceita pela maioria - e não toda a fundamentação - compõe a razão de decidir. Como se nota, há, na operação dos precedentes normativos pelo STF, certa confusão e certa hesitação que são produto da inexistência de uma cultura de precedentes com efeitos normativos e da pouca familiaridade com o instrumental adequado para lidar com tais precedentes.

Entretanto, na elaboração das súmulas vinculantes, o Supremo habitualmente produz verbetes que sintetizam a razão de decidir comum a diversos julgados sobre uma mesma matéria, aos quais é atribuída força normativa.

26 Nessa linha: STF, Primeira Turma, Rcl 21.858, rel. Min. Edson Fachin, DJe, 28.10.2015; Primeira Turma, Rcl 4454 AgR, rel. Min. Luís Roberto Barroso, DJe, 17.03.2015; Segunda Turma, Rcl 18.788 AgR, rel. Min. Celso de Mello, DJe, 22.09.2015;
Além disso, a adoção de precedentes normativos em matéria constitucional, tal como pretendida pelo Novo Código, passa necessariamente pelo reconhecimento de efeitos normativos à tese de direito que serve de base para a decisão. Esta é a única maneira de gerar um precedente normativo em sede de controle difuso da constitucionalidade, e o Novo CPC determinou expressamente que também as decisões proferidas em recursos extraordinários repetitivos produzirão efeitos normativos e possibilitarão a propositura de reclamação. Ora, nesse caso, não seria possível limitar o teor normativo ao dispositivo da decisão, já que este, no caso do controle difuso, apenas decide uma demanda concreta e proclama o direito subjetivo de alguém a alguma coisa. O conteúdo passível de aplicação a situações semelhantes, no caso do controle difuso, é justamente a exegese constitucional fixada pela Corte como premissa necessária para atingir suas conclusões.

Nesse contexto, é incoerente reconhecer a eficácia normativa da ratio decidendi na elaboração de súmulas vinculantes e nos precedentes proferidos no controle difuso e rejeitar a mesma eficácia à ratio decidendi em sede concentrada. A se manter a redação do CPC/2015 tal como se encontra hoje, o STF precisará repensar a eficácia transcendente dos motivos determinantes da decisão.

\subsection{Obiter dictum}

Toda e qualquer consideração jurídica constante da fundamentação, que trate de questão diversa daquela estritamente necessária para alcançar a decisão do caso concreto, como, por exemplo, argumentos levantados pelo relator, mas não acolhidos pela maioria, ou observações sobre como determinado membro do colegiado se posicionaria em questão próxima àquela posta pelo caso em exame constituem obiter dicta, ou seja, correspondem a meras considerações marginais, que não se prestam a compor a ratio decidendi.

É importante, portanto, compreender que nem toda fundamentação vincula. Só vincula a tese de direito necessária à solução da demanda concreta. Assim, autoriza-se o Judiciário a produzir norma, mas, diversamente do que ocorre com o Legislativo, a norma produzida pelo Judiciário, o precedente vinculante, só pode tratar especificamente da questão posta em juízo. Outras colocações que os magistrados desejem efetuar ou a antecipação de entendimentos sobre os casos futuros não vinculam, em respeito aos princípios do devido processo legal e da inércia da jurisdição. 
Entretanto, o fato de os dicta não produzirem efeitos vinculantes não significa que são juridicamente irrelevantes. Tanto esses quanto os votos vencidos têm importância argumentativa. A opinião de um desembargador ou de um juiz serve de exemplo e de reforço à defesa de posições ainda não consolidadas. Podem inspirar novas teses e antecipar posicionamentos futuros. As cortes podem se valer de um obiter dictum, ainda, para sinalizar sua inclinação a alterar uma determinada jurisprudência, em casos subsequentes, sem gerar grande surpresa.

\subsection{Distinção entre casos (distinguish)}

A aplicação de um precedente a um caso subsequente depende não apenas da identificação da sua ratio decidendi, mas também de uma avaliação quanto à semelhança entre os dois $\operatorname{casos}^{27}$. Uma nova causa pode apresentar fatos diferentes, mas juridicamente irrelevantes, circunstância em que se afirmará a identidade entre as duas ações e na qual, por consequência, a decisão da nova demanda deverá observar o entendimento proferido no caso anterior. Um novo caso pode, contudo, envolver situação de fato sutilmente diferente, porém a diferença pode ser relevante do ponto de vista jurídico. Há diferença juridicamente relevante quando a nova situação de fato atrair o debate sobre regras ou sobre princípios que não se aplicavam à situação anterior.

A título de ilustração, na ADC 4, a União requereu que o Supremo declarasse a constitucionalidade de uma norma que vedou o deferimento de antecipação de tutela

27 TRIBE, Laurence H.; DORF, Michael C. On reading the Constitution. Cambridge: Harvard University Press, 1991. p. 71 e ss.; LLEWELYN, Karl N. The Common Law tradition: deciding appeals. Boston: Little, Brown and Company, 1960. p. 77 e ss.; GOODHART, Arthur L. Determining the Ratio Decidendi of a case. Modern Law Review, London, v. 22, p. 117-124, 1959; DWORKIN, Ronald. O império do direito. Trad. Jefferson Luiz Camargo. São Paulo: Martins Fontes, 2003. p. 300 e ss.; SUMMERS, Robert S. Precedent in the United States (New York State). ). In: MACCORMICK, D. Neil; SUMMERS, Robert S. (Org.). Interpreting precedents: a comparative study. England: Dartmouth Publishing Company Limited; Ashgate Publishing Limited, 1997. p. 390-394; SCHAUER, Frederick. Precedent. p. 571605. Disponível em: <www.bsos.umd.edu/gvpt/CITE-IT/ Documents/Schauer\%201987\%20Precedent.pdf>. Acesso em: 20 dez. 2006; SCHAUER, Frederick. Rules: the rule of law and the Constitution. Constitutional Commentary, Minneapolis, v. 6, p. 69-85, 1989; FINE, Toni M. O uso do precedente e o papel do princípio do Stare Decisis no sistema legal norte-americano. Revista dos Tribunais, São Paulo, v. 89, n. 782 , p. $90-96$, dez. 2000, p. 247-258; SOUZA, Marcelo Alves Dias de. Do precedente judicial à súmula vinculante. Curitiba: Juruá, 2006. p. 142-153. contra a Fazenda Pública, caso implicasse em pagamento de vencimentos e/ou de vantagens ${ }^{28}$. A Corte entendeu pela constitucionalidade em tese da norma. Tempos depois, uma pensionista de servidor, de idade avançada, ajuizou ação requerendo antecipação de tutela para que fosse restabelecido o pagamento de parte de sua pensão, que teria sido ilegitimamente cortada. No mérito, havia jurisprudência do STF no sentido de que a supressão do pagamento era ilegítima. A liminar em favor da pensionista foi deferida em primeiro grau.

O ente público ajuizou, então, uma reclamação, diretamente no Supremo, alegando que a decisão proferida na $\mathrm{ADC} 4$ estava sendo descumprida, já que se deferira liminar em favor da pensionista para o pagamento de pensão, em desacordo com a norma que a vedou e que teve a sua validade confirmada pelo STF. Entretanto, a Corte observou que o caso específico tinha particularidades. Primeiramente, o pleito de restabelecimento do pagamento da verba estava alinhado com a jurisprudência do Supremo. Em segundo lugar, dada a idade avançada da autora, a impossibilidade de antecipação de tutela implicava negar-lhe o direito de acesso ao Judiciário porque a postulante poderia não viver até o momento da decisão de mérito. Assim, o caso colocava em questão normas e valores que não foram apreciados quando do deferimento da cautelar na ação declaratória - ao menos, não na mesma intensidade. Com base nesses fundamentos, a decisão reclamada foi mantida e a antecipação de tutela implementada ${ }^{29}$.

Nessa decisão o STF fez uma distinção entre o julgado proferido na ADC 4 e o caso que lhe foi trazido em reclamação. Destacou que a diferença de fato, embora parecesse pequena, colocava ao julgador conflito jurídico diverso daquele apreciado na $\operatorname{ADC} 4$, que não aludia especificamente a uma senhora de idade ou a verba sobre a qual o STF já havia reconhecido ser devido o pagamento. Tal conclusão de modo algum pode ser qualificada como mecânica, tampouco enseja uma reflexão sem sofisticação. Essas considerações demonstram que, também a identificação ou diferenciação entre casos, para fins de aplicação do precedente, depende de interpretação. E esta caberá, mais uma vez, ao juiz vinculado, o mesmo magistrado que pode não concordar com o precedente da corte vinculante e que, por conseguinte, desejaria desviar-se dele.

STF, DJU, 21.05.1999, ADC 4, rel. Min. Sydney Sanches. STF, DJU, 04.04.2003, Ag Rg na Rcl. no 1.132, rel. Min. Celso de Mello. 
Por isso e ao contrário do que se poderia imaginar, um sistema de precedentes com eficácia normativa não necessariamente implica redução do poder dos juízos vinculados. A observância de tais precedentes sempre dependerá, em alguma medida, da força persuasiva dos argumentos invocados pela corte vinculante, de sua capacidade de convencimento e da percepção de que se trata de um entendimento que realiza, em alguma medida, o ideal de justiça.

Quando os juízes vinculados têm a percepção de que um precedente está errado ou de que produz um resultado injusto, sua tendência será de interpretá-lo restritivamente, de reduzir seu âmbito de incidência, quer através da definição de uma ratio decidendi menos ampla, quer procurando efetuar uma distinção entre o caso que gerou o precedente e o novo caso submetido à sua apreciação. Com essa atitude, o magistrado vinculado procurará garantir a si próprio um espaço mais amplo de discrição para decidir o novo caso.

As sucessivas decisões que interpretarem restritivamente o precedente das cortes superiores, percebido como inadequado, gerarão uma massa de julgados divergentes e, eventualmente, de distinções inconsistentes, baseadas em argumentos que não se prestam efetivamente a justificar um tratamento diferenciado e que são utilizados como mera forma de evitar a aplicação de um entendimento que se considera incorreto. Sobretudo na hipótese dos precedentes normativos, essa massa de casos ensejará a propositura de reclamações junto ao tribunal vinculante, para que este imponha a eficácia do seu entendimento.

A continuada rejeição de um precedente normativo por parte das instâncias inferiores ensejará, por consequência, não apenas uma incongruência entre as decisões de casos semelhantes e um sentimento de incerteza no jurisdicionado sobre o direito efetivamente aplicado, como, igualmente, provocará uma enxurrada de reclamações na corte vinculante, comprometendo sua pauta, seu funcionamento, seu poder de agendar e apreciar os casos que considera efetivamente relevantes. Em decorrência desse mecanismo, a corte vinculante se verá compelida a dialogar com as demais instâncias, de modo a assegurar seu próprio funcionamento, sua estabilidade institucional, o respeito e o crédito reconhecido às suas decisões.

\subsection{Superação de precedentes (overruling)}

impede que uma corte venha a mudar seu entendimento no futuro. A superação de precedentes geralmente ocorre quando estes são socialmente incongruentes (e, portanto, não refletem a compreensão social sobre o que é justo) ou, ainda, quando são sistemicamente inconsistentes (porque conflita com outras normas, com outras decisões do órgão vinculante ou, ainda, com outras decisões reiteradamente proferidas pelas instâncias inferiores). A sistemática rejeição de um precedente normativo e as distinções inconsistentes entre casos pelas instâncias vinculadas (atitude estratégia para tentar evitar a sua aplicação) podem levar o tribunal vinculante a rever ou moderar sua decisão, a fim de viabilizar a adesão dos órgãos vinculados. Nota-se, portanto, que a adoção de precedentes normativos não necessariamente reduzirá a relevância dos argumentos e do poder de convencimento dos magistrados que compõem as instâncias inferiores ${ }^{30}$.

TRIBE, Laurence H. American constitutional law. 3. ed. New York: Foundation Press, 2000, v. 1, p. 236 e ss.; RORIVE, Isabelle. La rupture de la House of Lords avec un strict principe du Stare Decisis dans le contexte d'une réflexion sur l'accélération du temps juridique. In: GERARD, Philippe; OST, François; VAN DE KERCHOVE, Michel (Org.). Laccélération du temps juridique. Bruxelles: Facultés Universitaires Saint-Louis, 2000. monaghanp. 816 e ss.; MONAGHAN, Henry Paul. Stare Decisis and constitutional adjudication. Columbia Law Review, New York, v. 88, n. 4, p. 723-773, May 1988, p. 758 e ss.; SUMMERS, Robert S. Precedent in the United States (New York State). In: MACCORMICK, D. Neil; SUMMERS, Robert S. (Org.). Interpreting precedents: a comparative study. England: Dartmouth Publishing Company Limited; Ashgate Publishing Limited, 1997. p. 374 e ss.; EISENBERG, Melvin Aron. The nature of the common law. Cambridge: Harvard University Press, 1988. p.104 e ss.; CARDOZO, Benjamin N. The nature of the judicial process. New York: Dover Publications, 2005. p. 147 e ss.; COLE, Charles D. Stare Decisis na cultura jurídica dos Estados Unidos: o sistema de precedente vinculante do Common Law. Trad. Maria Cristina Zucchi. Revista dos Tribunais, São Paulo, v. 87, n. 752, p. 11-21, jun. 1998, p. 18; ALEXANDER, Larry. Constrained by precedent. Southern California Law Review, Los Angeles, v. 63, p. 1-64, nov. 1989, p. 1-64; HANSFORD, Thomas G.; SPRIGGS II, James F. Explaining the overruling of U.S. Supreme Court precedent. p. 23-24. Disponível em: <http:// repositories.cdlib.org/csls/lss/9/>. Acesso em: 20 set. 2005; HANSFORD, Thomas. G.; SPRIGGS II, James F . The politics of precedent on the U.S. Supreme Court. p. 19. Disponível em: <http://psfaculty.ucdavis.edu/spriggs/The_Politics_of_Precedent_FINAL.pdf $>$. Acesso em: 20 set. 2005; SILVA, Celso de Albuquerque. Do efeito vinculante: sua legitimação e aplicação. Rio de Janeiro: Lumen Juris, 2005. p. 262-284; SOUZA, Marcelo Alves Dias de. Do precedente judicial à súmula vinculante. Curitiba: Juruá, 2006. p. 148153. 


\section{Atribuir efeitos normativos às decisões pro- feridas pelo STF em sede de recurso repetiti- vo foi uma boa escolha?}

É certo que o não cabimento de reclamação contra o descumprimento das decisões proferidas pelo STF em sede de repercussão geral e de recurso repetitivo produz um compreensível sentimento de perplexidade na comunidade jurídica. Afinal, se o propósito dos institutos era evitar que a Corte tivesse de julgar um grande volume de casos iguais e assegurar, por outro lado, o respeito à interpretação produzida pelo Tribunal em sede constitucional, parece incoerente não reconhecer a possibilidade de ajuizamento de reclamação caso as instâncias inferiores deixem de seguir o precedente fixado.

A razão pela qual o Supremo negou a possibilidade de reclamação no caso é, sobretudo, pragmática: o Tribunal já enfrentava enorme dificuldade de gerenciar os processos de que dispunha, quando da entrada em vigor do instituto da repercussão geral, e não é da noite para o dia que se constrói, nas instâncias inferiores e tampouco no próprio STF, uma cultura de respeito ao precedente. A Corte temeu, por isso, ser invadida por uma onda de reclamações provenientes de todo e qualquer caso em que eventualmente se considerasse equivocada a aplicação de uma questão já decidida pelo STF em recurso repetido ${ }^{31}$.

Nesse contexto, a adoção de súmulas vinculantes para conferir força normativa às decisões mais relevantes proferidas pelo Supremo Tribunal Federal em sede repetitiva parecia uma boa solução. De um lado, possibilitaria que o Tribunal garantisse a efetividade daqueles entendimentos que considerasse imprescindíveis, através da edição seletiva de súmulas vinculantes. De outro, evitaria que todas as matérias repetitivas gerassem precedentes com efeitos normativos, a fim de evitar o ajuizamento de um grande número de reclamações no STF. As súmulas vinculantes pareciam, assim, um instrumento adequado para conciliar o po-

31 Cf. STF, Pleno, Rcl 10.973, rel. Min. Ellen Gracie, DJe, 06.06.2011, em que, a relatora ponderou, a respeito do (des)cabimento de reclamação em sede de repercussão geral: "Se, conforme propõe Vossa Excelência, nós abrirmos a porta da reclamação a toda e qualquer divergência com relação à jurisprudência do Supremo, nós teremos um resultado contraproducente da Emenda Constitucional no 45, porque, ao invés de termos, como tínhamos em 2007, cento e cinquenta mil processos perante uma Suprema Corte, nós teremos cento e cinquenta mil reclamações". der do Tribunal de gerenciar a sua própria agenda com a adoção de precedentes normativos em alguns casos repetitivos ${ }^{32}$.

Entretanto, não foi essa a escolha do Novo Código de Processo Civil. E é preciso reconhecer que tampouco o STF chegou a adotar esse tipo de abordagem com o uso das súmulas vinculantes. Talvez se a Corte tivesse apresentado postura diversa não se teria ido tão longe no novo diploma, no que respeita às eficácia normativa das decisões proferidas em recurso extraordinário repetitivo. É certo que os precedentes normativos podem constituir um instrumento valioso na afirmação de valores que são caros ao ordenamento jurídico brasileiro. Mas não é menos certo, que, tal como adotados tais precedentes, gerou-se considerável risco para a gestão do já enorme acervo de processos do Supremo. E deve-se ter em conta que não é possível ao legislador ordinário, a pretexto de dispor sobre normas processuais, criar competência que impossibilita o cumprimento pela Corte de suas missões constitucionais.

\section{Por que adotar um sistema de precedentes normativos?}

Se um sistema de precedentes vinculantes se sujeita a todas as interpretações, indeterminações e percalços indicados acima, qual é a vantagem de adotá-lo? Entende-se que a adoção de tal sistema promove três valores centrais: a segurança jurídica, a isonomia e a eficiência. A segurança jurídica é assegurada porque a orientação proferida por meio da ratio decidendi tende a ser mais precisa e, portanto, menos genérica que aquela veiculada pela lei, já que é delimitada pelo caso concreto. Esse primeiro aspecto facilitaria a compreensão e o prévio conhecimento do direito pelo jurisdicionado.

A promoção da isonomia decorre do fato de se assegurar a todos aqueles que apresentem casos semelhantes o mesmo tratamento, aspecto essencial em um Estado democrático de direito. Por fim, a maior eficiência do sistema é alcançada, na medida em que os juízes passem a aplicar os precedentes já proferidos aos novos casos e, por consequência, comecem a alocar seu tempo, sua energia e os recursos da instituição a que pertencem para decidir

2 Na mesma linha, cf. BARROSO, Luis Roberto. O controle de constitucionalidade no direito brasileiro. São Paulo: Saraiva, 2015. 
e influenciar as questões sobre as quais ainda não há um posicionamento normativo.

Uma observação, contudo, precisa ser feita. A cultura do respeito aos precedentes judiciais deve ser conquistada não apenas pelos juízos vinculados, tantas vezes criticados por sua “insubordinação" ou por sua jurisprudência vacilante. A cultura de respeito aos precedentes judiciais precisa ser igualmente desenvolvida nas cortes vinculantes, através de decisões claras, consistentemente fundamentadas e prestigiadas por seus próprios membros, que não podem se dar ao luxo de alterá-las a cada mudança de composição ou de acordo com as conveniências políticas de momento. Sem isso, a tentativa de instalação dos precedentes normativos gerará um emaranhado caótico de decisões, incidentes, recursos e reclamações que não contribuirão em nada para o aperfeiçoamento do sistema ${ }^{33}$.

A implantação bem sucedida de tal ferramenta depende, portanto, antes de mais nada, de que os tribunais superiores e o Supremo Tribunal Federal, acima de todos, aperfeiçoe seu processo decisório e levante o nível de sua atuação. Em síntese, é preciso que o STF compreenda que o respeito às suas decisões pelas instâncias vinculadas depende da qualidade e do respeito que o próprio Tribunal reconhecerá às suas decisões.

\section{Conclusão}

Com o Novo Código de Processo Civil, a eficácia normativa passa a ser a regra no que respeita às decisões proferidas pelo Supremo Tribunal Federal em matéria constitucional. Esse tipo de eficácia deixa de se circunscrever às decisões proferidas em controle concentrado e às súmulas vinculantes e passa a alcançar inclusive os julgados em matéria de recurso extraordinário repetitivo. O diploma amplia, portanto, os casos de precedentes vinculantes e, mesmo nas situações em que não cabe reclamação, determina a observância das súmulas simples do STF, do STJ e dos entendimentos do pleno dos tribunais. Essa mudança busca dar resposta à sobrecarga experimentada pelo Judiciário, à necessidade de racionalizar a alocação de seus recursos e a atuação dos juízes, bem

33 VOJVODIC, Adriana de Moraes; MACHADO, Ana Mara França; CARDOSO, Evorah Lusci Costa. Escrevendo um romance, primeiro capítulo: precedentes e processo decisório no STF. Rev. Direito GV [online], 2009, v. 5, n. 1, p. 2144. Disponível em: <http://www.scielo.br/pdf/rdgv/v5n1/ a02v5n1.pdf $\geq$. Acesso em: 10 nov. 2015. como à expectativa de que casos iguais sejam tratados de maneira idêntica.

O novo código não encontrará, na partida, uma cultura jurídica adaptada à operação com precedentes normativos. Trata-se, portanto, de uma mudança que desafia os juristas, os juízes, os advogados, a academia a desenvolver instrumentos hermenêuticos e argumentativos voltados a uma nova realidade e a novos desafios. Seu resultado pode se revelar positivo se conduzir à efetiva formação de uma cultura de respeito à jurisprudência. Mas essa cultura não depende apenas das instâncias vinculadas. Para que ela se implemente, o próprio STF precisa contribuir com decisões claras, fundamentos consistentes e respeito à estabilidade de seus próprios julgados.

\section{Referências}

ALEXANDER, Larry. Constrained by precedent. Southern California Law Review, Los Angeles, v. 63, p. 1-64, Nov. 1989.

ALEXY, Robert; DREIER, Ralf. Precedent in the Federal Republic of Germany. In: MACCORMICK, D. Neil; SUMMERS, Robert S. (Org.). Interpreting precedents: a comparative study. England: Dartmouth Publishing Company Limited; Ashgate Publishing Limited, 1997. p. 17-64.

BARROSO, Luis Roberto. O controle de constitucionalidade no direito brasileiro. São Paulo: Saraiva, 2015.

CARDOZO, Benjamin N. The nature of the judicial process. New York: Dover Publications, 2005.

COLE, Charles D. Stare Decisis na cultura jurídica dos Estados Unidos: o sistema de precedente vinculante do Common Law. Trad. Maria Cristina Zucchi. Revista dos Tribunais, São Paulo, v. 87, n. 752, p. 11-21, jun. 1998.

DWORKIN, Ronald. O império do direito. Trad. Jefferson Luiz Camargo. São Paulo: Martins Fontes, 2003.

DWORKIN, Ronald. Levando os direitos a sério. Trad. Nelson Boeira. São Paulo: Martins Fontes, 2002.

EISENBERG, Melvin Aron. The nature of the Common Law. Cambridge: Harvard University Press, 1988.

FINE, Toni M. O uso do precedente e o papel do princípio do Stare Decisis no sistema legal norte-americano. Revista dos Tribunais, São Paulo, v. 89, n. 782, p. 90-96, dez. 2000. 
GOODHART, Arthur L. Determining the Ratio Decidendi of a case. Modern Law Review, London, v. 22, p. 117124, 1959.

HANSFORD, Thomas. G.; SPRIGGS II, James F. Explaining the overruling of U.S. Supreme Court precedent. Disponível em: <http://repositories.cdlib.org/csls/lss/9/>. Acesso em: 20 set. 2005.

HANSFORD, Thomas. G.; SPRIGGS II, James F. The politics of precedent on the U.S. Supreme Court. Disponível em: <http://psfaculty.ucdavis.edu/spriggs/The_Politics_ of_Precedent_FINAL.pdf $>$. Acesso em: 20 set. 2005.

LLEWELYN, Karl N. The Common Law tradition: deciding appeals. Boston: Little, Brown and Company, 1960.

MALTZ, Earl. The nature of precedent. North Carolina Law Review, Chapel Hill, v. 66, p. 367-392, Jan. 1988.

MACCORMICK, Neil. Argumentação jurídica e teoria do direito. Trad. Waldéa Barcellos. São Paulo: Martins Fontes, 2006.

MARSHALL, Geoffrey. What is binding in a precedent. In: MACCORMICK, D. Neil; SUMMERS, Robert S. (Org.). Interpreting precedents: a comparative study. England: Dartmouth Publishing Company Limited; Ashgate Publishing Limited, 1997. p. 503-518.

MARTINS, Yves Gandra; MENDES, Gilmar Ferreira. Eficácia das decisões do Supremo Tribunal Federal. Cadernos de Direito Tributário e Finanças Públicas, Revista dos Tribunais, São Paulo, v. 1, n. 2, p. 7-11, jan./mar. 1993.

MELLO, Patrícia Perrone Campos. Precedentes: o desenvolvimento do direito no constitucionalismo contemporâneo. Rio de Janeiro: Renovar, 2008.

MENDES, Gilmar Ferreira. O papel do Senado Federal no controle de constitucionalidade: um caso clássico de mutação constitucional. Revista de Informação Legislativa, Senado Federal, Brasília, v. 162, p. 149-168.

MONAGHAN, Henry Paul. Stare Decisis and constitutional adjudication. Columbia Law Review, New York, v. 88, n. 4, p. 723-773, May 1988.

NERY JUNIOR, Nelson; NERY, Rosa Maria de Andrade. Comentários ao Código de Processo Civil. São Paulo: Revista dos Tribunais, 2015.
RE, Edward D. Stare Decisis. Revista de Processo, São Paulo, v. 19, n. 73, p. 47-54, jan./mar. 1994.

RORIVE, Isabelle. La rupture de la House of Lords avec un strict principe du Stare Decisis dans le contexte d'une réflexion sur laccélération du temps juridique. In: GERARD, Philippe; OST, François; VAN DE KERCHOVE, Michel (Org.). L’accélération du temps juridique. Bruxelles: Facultés Universitaires Saint-Louis, 2000. p. 801-836.

RUIZ MIGUEL, Alfonso; LAPORTA, Francisco J. Precedent in Spain. In: MACCORMICK, D. Neil; SUMMERS, Robert S. (Org.). Interpreting precedents: a comparative study. England: Dartmouth Publishing Company Limited; Ashgate Publishing Limited, 1997. p. 253-291.

SCHAUER, Frederick. Precedent. p. 571-605. Disponível em: <www.bsos.umd.edu/gvpt/CITE-IT/Documents/ Schauer\%201987\%20Precedent.pdf $>$. Acesso em: $20 \mathrm{dez}$. 2006.

SCHAUER, Frederick. Rules: the rule of law and the Constitution. Constitutional Commentary, Minneapolis, v. 6, p. 69-85, 1989.

SILVA, Celso de Albuquerque. Do efeito vinculante: sua legitimação e aplicação. Rio de Janeiro: Lumen Juris, 2005.

SOUZA, Marcelo Alves Dias de. Do precedente judicial à súmula vinculante. Curitiba: Juruá, 2006.

SUMMERS, Robert S. Precedent in the United States (New York State). In: MACCORMICK, D. Neil; SUMMERS, Robert S. (Org.). Interpreting precedents: a comparative study. England: Dartmouth Publishing Company Limited; Ashgate Publishing Limited, 1997. p. 355-405.

TARUFFO, Michele; LA TORRE, Massimo. Precedent in Italy. In: MACCORMICK, D. Neil; SUMMERS, Robert S. (Org.). Interpreting precedents: a comparative study. England: Dartmouth Publishing Company Limited; Ashgate Publishing Limited, 1997. p. 141-187.

TRIBE, Laurence H. American constitutional law. 3. ed. New York: Foundation Press, 2000. v. 1.

TRIBE, Laurence H.; DORF, Michael C. On reading the Constitution. Cambridge: Harvard University Press, 1991. 